\title{
T3 Vertebra
}

National Cancer Institute

\section{Source}

National Cancer Institute. T3 Vertebra. NCI Thesaurus. Code C33725.

The third thoracic vertebra counting from the top down. 